03

\title{
Мультиочаговый поджиг газовой горючей смеси подкритическим СВЧ разрядом с развитой стримерной структурой
}

\author{
() К.В. Александров, Н.И. Буслеев, Л.П. Грачев, И.И. Есаков, А.А. Раваев \\ Акционерное общество „Московский радиотехнический институт РАН“, \\ 117519 Москва, Россия \\ e-mail: grachev@mrtiran.ru
}

(Поступило в Редакцию 28 апреля 2017 г.)

Описаны экспериментальные исследования возможности использования реализованного в квазиоптическом СВЧ пучке электрического разряда с развитой стримерной структурой для мультиочагового поджига пропан-воздушной горючей смеси. Импульсный СВЧ разряд зажигается на внутренней поверхности заполненной горючей смесью кварцевой трубки, помещенной в СВЧ пучок с подпробойным исходным уровнем поля. Пробой газа инициируется электромагнитным вибратором. В опытах исследован вид разряда в зависимости от уровня СВЧ поля, определен нижний концентрационный предел воспламенения пропанвоздушной смеси разрядом этого вида, и сравнена динамика горения горючей смеси при локальном и мультиочаговом ее поджиге.

DOI: $10.21883 /$ JTF.2018.02.45403.2322

\section{Введение}

В настоящее время рассматриваются различные варианты детонационного режима сжигания топливной смеси. Теоретически показано, что именно такой режим может обеспечить энергетически эффективное ее сгорание [1]. При этом, если скорость фронта обычного дефлаграционного горения, например, пропан-воздушной смеси имеет масштаб одного $\mathrm{m} / \mathrm{s}$, то скорость фронта ее детонационного горения превышает $1 \mathrm{~km} / \mathrm{s}$. Такой режим, как правило [2], реализуется в предварительно заполненной горючей смесью трубчатой камере сгорания. При этом один ее конец открыт, а другой закрыт. Поджиг смеси осуществляется около закрытого конца, и для реализации детонационного режима распространения пламени необходимы сравнительно высокие энергетические затраты. Кроме того, в реальных схемах переход от зоны поджига с режимом дефлаграционного горения в детонационный режим пространственно достаточно протяженный. Именно над решением этих проблем и работают сейчас разработчики детонационных двигателей [3].

В настоящее время достаточно подробно изучен газовый электрический разряд в квазиоптическом СВЧ пучке [4]. Причем такой разряд может быть зажжен, например, в воздухе атмосферного давления $p$ при амплитуде электрической составляющей исходного поля $E_{0}$ в несколько $\mathrm{kV} / \mathrm{cm}$. Она существенно меньше минимальной критической величины пробойного поля воздуха атмосферного давления $E_{\mathrm{cr}} \approx 30 \mathrm{kV} / \mathrm{cm}$. Пробой воздуха в этом случае инициируется, например, помещением в СВЧ пучок линейного электромагнитного (ЭМ) вибратора. При этом для СВЧ поля, например, с длиной волны $\lambda \approx 10 \mathrm{~cm}$ при $E_{0} \geq 1.5 \mathrm{kV} / \mathrm{cm}$ зажигаемый разряд является динамическим объемным стримерным объектом. Его разрядный фронт распространяется от
ЭМ вибратора - инициатора СВЧ пробоя - навстречу возбуждающей разряд СВЧ волне со скоростью $v_{\mathrm{fr}}$ в несколько $\mathrm{km} / \mathrm{s}$. Отдельные локальные распределенные в пространстве участки этого разряда имеют газовую температуру $T$ в тысячи градусов.

Целью описываемых в настоящей работе экспериментальных исследований и было определение возможности использования уникальных параметров данного вида разряда по пространственным характеристикам, величин $v_{\text {fr }}$ и $T$ для реализации мультиочагового поджига газовой пропан-воздушной горючей смеси, т.е. возможности приближения к детонационному режиму ее сгорания.

В ходе выполнения экспериментов были определены количественные параметры используемого в них квазиоптического СВЧ пучка; определены параметры зажигаемого в воздухе при атмосферном $p$ на внутренней поверхности кварцевой трубки инициированного ЭМ вибратором подкритического СВЧ разряда в зависимости от степени подкритичности поля; определен нижний концентрационный предел воспламенения пропанвоздушной горючей смеси при ее поджиге данным видом разряда; реализован режим дефлаграционного горения заполняющей трубку пропан-воздушной смеси; и режим ее горения при мультиочаговом поджиге.

\section{Экспериментальные условия}

Эксперименты выполнялись на описанной в работе [4] установке с $\lambda=8.9 \mathrm{~cm}$. Ее схема приведена на рис. 1.

В опытах использовались одиночные СВЧ импульсы длительностью $\tau_{\text {pul }}=40 \mu \mathrm{s}$. При этом сформированный линейно поляризованный ЭМ пучок характерным диаметром $60 \mathrm{~cm}$ излучается в цилиндрическую СВЧ безэховую герметичную рабочую камеру. Вектор $\mathbf{E}_{0}$ ЭМ 


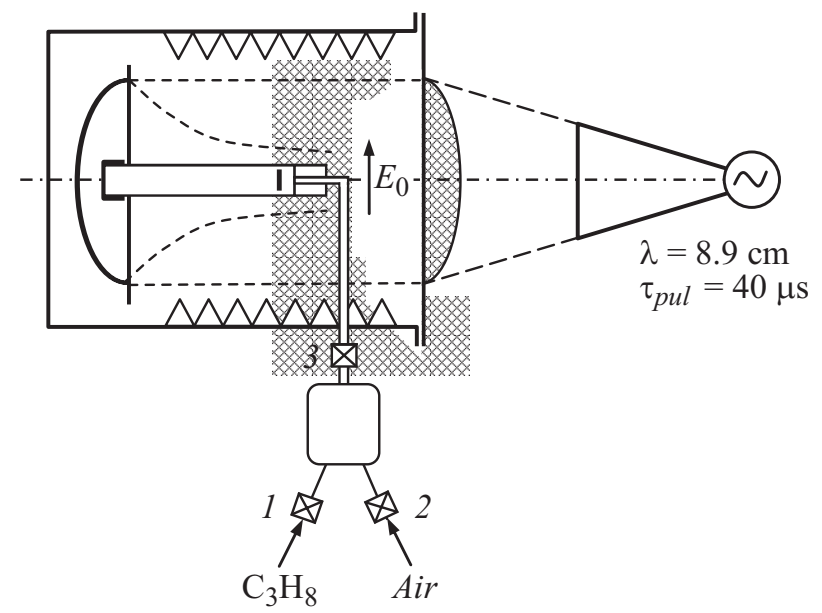

Рис. 1. Схема проведения экспериментов.

пучка вертикален. Пучок падает на сферически вогнутое металлическое зеркало и, отразившись от него, фокусируется. Расстояние фокусной „точки“ от среза зеркала $x_{\mathrm{f}}=10.5 \mathrm{~cm}$. В плоскости $y-z$, проведенной через область пучка при $x=x_{\mathrm{f}}$ и перпендикулярной волновому вектору $\mathbf{k}$ ЭМ пучка, распределение амплитуды поля имеет вид $E_{0}=E_{0 \text { max }} e^{-\left(y / y_{0}\right)^{2}}$ и $E_{0}=E_{0 \max } e^{-\left(z / z_{0}\right)^{2}}$, где ось $y$ параллельна вектору $\mathbf{E}_{0}$, ось $z-$ перпендикулярна ему, а их начало совмещено с осью пучка. В этих зависимостях размер $y_{0}=5.2 \mathrm{~cm}$, а $z_{0}=2.5 \mathrm{~cm}$.

В опытах, как показано на рис. 1, в фокусную область ЭМ пучка вдоль его оси может помещаться кварцевая трубка внутренним диаметром $d=36 \mathrm{~mm}$ и наружным $40 \mathrm{~mm}$. Дальний от зеркала торец трубки герметизирован диэлектрической пробкой. По оси она имеет отверстие диаметром $1.5 \mathrm{~mm}$. К пробке прикреплена диэлектрическая вспомогательная трубка, по которой к этому отверстию может подводиться заполняющая кварцевую трубку газовая пропан-воздушная смесь. Обращенный к зеркалу торец кварцевой трубки герметизируется полиэтилентерефтолатной пленкой толщиной $0.25 \mathrm{~mm}$. Она на длине в $5 \mathrm{~mm}$ прикрепляется к наружной поверхности кварцевой трубки вакуумной замазкой. Внутри этой трубки на расстоянии $260 \mathrm{~mm}$ от обращенного к зеркалу ее торца к ее цилиндрической боковой поверхности „вдоль“ вектора $\mathbf{E}_{0}$ прикреплен ЭМ вибратор. Он выполнен из медного провода диаметром $2 a=0.35 \mathrm{~mm}$ и длиной $2 l=45 \mathrm{~mm}$. Расстояние от инициатора до торцевой поверхности заглушающей трубку пробки равно $24 \mathrm{~mm}$. Из приведенных размеров следует, что заполняемый газовой смесью объем кварцевой трубки $V_{p}=290 \mathrm{~cm}^{3}$.

Как показано на рис. 1, система заполнения кварцевой трубки газовой смесью содержит вспомогательный баллон объемом $V_{b}=1.2 \cdot 10^{3} \mathrm{~cm}^{3}$. Баллон имеет три „клапана“. Через один из них он заполняется пропаном, через второй в эту систему может подаваться воздух из атмосферы, а через третий газовая смесь может по- даваться в объем кварцевой трубки. Внутренний объем тракта, подводящего газ от вспомогательного баллона к кварцевой трубке, $V_{\mathrm{ad}}=30 \mathrm{~cm}^{3}$.

\section{Результаты экспериментов}

Первоначально экспериментально была определена зависимость величины амплитуды электрической составляющей СВЧ волны $E_{0}$ в рабочей области ЭМ пучка вдоль его оси. Эти опыты проводились без кварцевой трубки. В них последовательно на различных расстояниях $x$, отсчитываемых от среза зеркала, помещался металлический шарик диаметром $5 \mathrm{~mm}$. Шарик по оси имел отверстие диаметром $1 \mathrm{~mm}$, и подвешивался на пропущенной через это отверстие капроновой нити, перпендикулярной вектору $\mathbf{E}_{0}$. Заполненная атмосферным воздухом рабочая камера установки может откачиваться. В опытах с точностью 3 Torr определялось максимальное давление воздуха $p_{\mathrm{br}}$, при котором шарик начинал инициировать СВЧ пробой. При этом для обеспечения наличия начальных электронов в приполярных пробойных областях шарика с полем $E>E_{\mathrm{cr}}$ в течение СВЧ импульса он облучался ультрафиолетовым (УФ) излучением. Полученные значения $p_{\mathrm{br}}$ по изложенной в работе [4] методике дали значения $E_{0}(x)$. Соответствующий график помещен на рис. 2.

Амплитуда поля $E_{0}$ при $x=x_{\mathrm{f}}$, соответствующая $E_{0 \max }$, при известном поперечном распределении поля позволяет рассчитать используемую в экспериментах мощность СВЧ пучка:

$$
P_{\text {beam }}\left(E_{0 \max }^{2} / 2 Z_{0}\right)\left(\pi y_{0} z_{0} / 2\right)=625 \mathrm{~kW},
$$

где $Z_{0}=120 \pi \Omega-$ волновое сопротивление свободного пространства.

Из рис. 2 и данных, приведенных в работе [4], следует, что при реализации в этом пучке инициированного СВЧ разряда в воздухе при атмосферном $p$ в свободном пространстве и на поверхности диэлектрической пластины в исследованном диапазоне $x$, т.е. величин $E_{0}$, он будет соответствовать подкритическому и глубоко подкритическому видам СВЧ разряда. Это разряды с

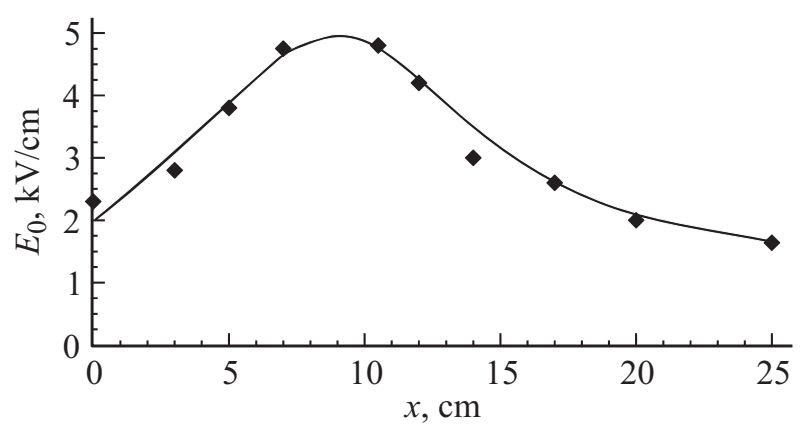

Рис. 2. Зависимость амплитуды электрической составляющей ЭМ волны вдоль оси квазиоптического СВЧ пучка. 


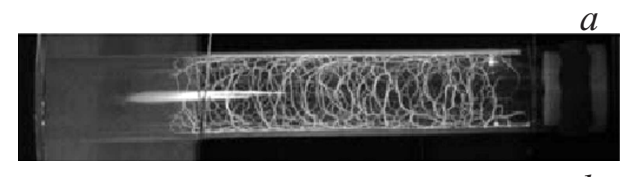

$E_{0}=2.4 \mathrm{kV} / \mathrm{cm}$

$180 \mathrm{~mm}$

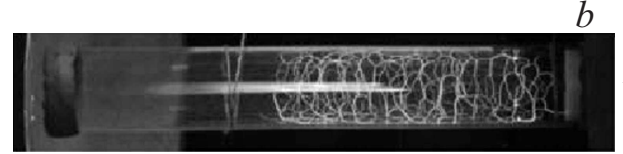

$E_{0}=2 \mathrm{kV} / \mathrm{cm}$

$200 \mathrm{~mm}$

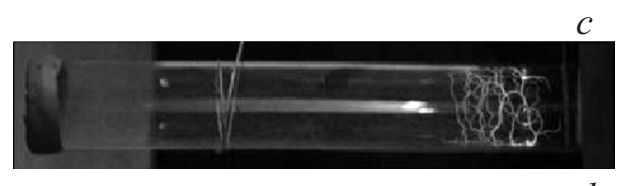

$E_{0}=1.85 \mathrm{kV} / \mathrm{cm}$

$210 \mathrm{~mm}$

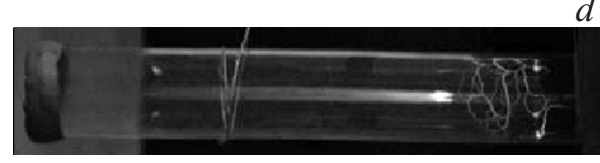

$E_{0}=1.75 \mathrm{kV} / \mathrm{cm}$

$220 \mathrm{~mm}$

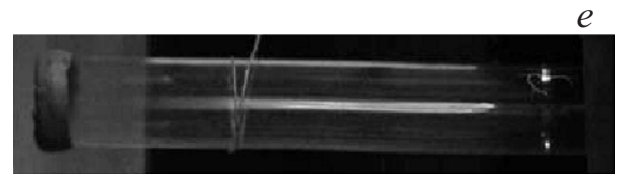

$E_{0}=1.7 \mathrm{kV} / \mathrm{cm}$

$225 \mathrm{~mm}$

Рис. 3. Виды инициированного ЭМ вибратором подкритического СВЧ разряда с поверхностно развитой по внутренней поверхности кварцевой трубки стримерной структурой и глубоко подкритического СВЧ разряда, привязанного к концам ЭМ вибратора.

пространственно развитой стримерной структурой и разряды со стримерными каналами, горящими только около концов инициатора. В рамках описываемых исследований был исследован вид этого разряда в зависимости от подкритичности поля при помещении ЭМ вибратора инициатора СВЧ пробоя воздуха - уже на внутренней поверхности кварцевой трубки.

В этих опытах, как показано на рис. 1, в СВЧ пучок помещалась кварцевая трубка с ЭМ вибратором, и в последовательных СВЧ импульсах трубка смещалась вдоль оси пучка. При этом при каждом расстоянии $x$ от среза зеркала до ЭМ вибратора производилась фоторегистрация зажигаемого разряда. Соответствующие фотографии приведены на рис. 3. На нем указаны конкретные размеры $x$ и соответствующие им величины $E_{0}$. Геометрическим масштабом изображений может служить наружный диаметр трубки.

На фотографиях СВЧ излучение распространяется слева направо; вектор $\mathbf{E}_{0}$ вертикален; с левой стороны находится загерметизированный пленкой торец трубки; с правой - яркие взаимно вертикальные точки являются плазменными образованиями, находящимися у концов ЭМ вибратора; горизонатальная яркая линия вдоль оси трубки является отблеском от элементов освещения помещения. Фотографии констатируют, что реализующийся разряд является плазменным объектом, имеющим стримерную структуру. Его размер вдоль трубки $L_{\text {dis }}$ зависит от величины поля $E_{0}$. На рис. $3, e$, соответ- ствующем $E_{0} \approx 1.7 \mathrm{kV} / \mathrm{cm}$, стримерные каналы разряда в течение всей длительности СВЧ импульса $\tau_{\text {pul }}$ остаются практически привязанными к концам ЭМ вибратора. Как следует из рис. $3, d$ и рис. $3, c$, они лишь незначительно отходят от них и в диапазоне $E_{0}$ от 1.75 до $1.85 \mathrm{kV} / \mathrm{cm}$. Разряд начинает распространяться навстречу СВЧ излучению лишь при $E_{0} \gtrsim 2 \mathrm{kV} / \mathrm{cm}$. По рис. $3, a$, соответствующему $E_{0} \approx 2.4 \mathrm{kV} / \mathrm{cm}$, можно оценить протяженность разрядной области величиной $L_{\mathrm{dis}} \approx 16 \mathrm{~cm}$. Она дает среднюю по экспериментальным значениям величин $E_{0}$ на этом участке ЭМ пучка скорость распространения разрядного фронта $v_{\text {dis }}=4 \cdot 10^{5} \mathrm{~cm} / \mathrm{s}$.

В контрольном эксперименте была проведена фоторегистрация внутренней полости кварцевой трубки при горении в ней СВЧ разряда при расположении вибратора на размере $x=18 \mathrm{~cm}$. В этом опыте герметизирующая пленка трубки была снята, и около открытого торцевого конца трубки под углом в $45^{\circ}$ к ее оси располагалось плоское зеркало размером $50 \times 50 \mathrm{~mm}$. Фотографировалось изображение на зеркале. Оно показало, что разрядные каналы расположены лишь на внутренней поверхности кварцевой трубки, т.е. зажигаемый стримерный СВЧ разряд является поверхностным.

В экспериментах был определен нижний предел зоны воспламенения пропан-воздушной горючей смеси при ее поджиге данным видом разряда.

Эти опыты выполнялись в следующей последовательности. Первоначально все элементы, включающие кварцевую трубку, тракт ее заполнения газовой смесью и вспомогательный баллон, откачивались до давления, меньшего 3 Torr. Затем вспомогательный баллон заполнялся пропаном до заданного давления $p_{\mathrm{b} 0}$, не превышающего 20 Torr, и баллон дозаполнялся воздухом до атмосферного давления $p_{0}$. После этого клапан заполнения кварцевой трубки открывался, и смесь заполняла все элементы. При этом давление газа в них устанавливалось несколько меньшим атмосферного значения, и уже весь тракт дозаполнялся воздухом до атмосферного $p_{0}$. После чего мог включаться СВЧ импульс.

В этих опытах положение кварцевой трубки вдоль оси пучка задавало размер $x=11 \mathrm{~cm}$. Как следует из рис. 2 и 3, при этом значении $x$ будет реализовываться протяженный вдоль трубки СВЧ разряд с развитой стримерной структурой.

Опыты начинались с $p_{\mathrm{b} 0}=9$ Torr. При этом значении $p_{\mathrm{b} 0}$ разряд не поджигал газовую смесь. Затем $p_{\mathrm{b} 0}$ увеличивалось с шагом в 3 Torr до давления $p_{\mathrm{b} 0}=18$ Torr, и при каждом его значении включался СВЧ импульс. Разряд поджег смесь только при $p_{\mathrm{b} 0}=15$ Torr. После этого процесс повторялся, начиная с $p_{\mathrm{b} 0}=13$ Torr уже с шагом в 1 Torr. При этом при $p_{\mathrm{b} 0}=13$ и 14 Torr разряд не поджигал смесь. Он поджег ее только при $p_{\mathrm{b} 0}=15$ Torr. Расчеты показали, что это граничное значение $p_{\mathrm{b} 0}$ задает весовое соотношение пропана и воздуха в кварцевой трубке $r_{\min }=G_{\text {prop }} / G_{\text {air }} \approx 0.4 / 16$, что, естественно, ниже стехиометрического значения 
$r_{0}=1 / 16$. Полученное значение $r_{\min }$ практически совпало с известной величиной нижней границы воспламенения пропан-воздушной горючей смеси $r_{\min }=0.38 / 16$ [5].

В следующих опытах исследовался процесс горения этой смеси при ее поджиге только у герметизированного диэлектрической пробкой конца кварцевой трубки. Эти опыты проводились при $p_{\mathrm{b} 0}=18$ Torr, т.е. при $r=0.48 / 16$, что несколько больше определенной границы $r_{\min }$. Первоначально расположение трубки задавало размер $x=22.5 \mathrm{~cm}$. При этом вид разряда соответствует рис. 3, e. В этом случае разряд не поджигал смесь. Затем трубка смещалась в сторону фокусирующего зеркала, обеспечив размер $x=22 \mathrm{~cm}$, что соответствует виду разряда, приведенному на рис. $3, d$. В этом случае разряд уже поджигал смесь.

Этот результат экспериментов качественно можно прокомментировать следующим образом. На практике для поджига горючей смеси необходимо не только, чтобы температура газа $T$ в области ее поджига была больше температуры поджига $T_{\mathrm{ign}}$, но и энергия поджига была больше некой минимальной граничной величины [5]. Сравнивая рис. 3, $d$ и 3,e, можно предположить, что если первое условие выполняется и при $x=22.5 \mathrm{~cm}$, то второе начинает выполняться только при $x<22.5 \mathrm{~cm}$. Количественное подтверждение этого предположения требует дальнейшей проработки. В то же время опытная констатация самого факта поджига горючей смеси показывает, что температура $T$ отдельных плазменных участков разряда, прилегающего к кварцевой поверхности, больше температуры поджига пропан-воздушной горючей смеси $T_{\text {ign }} \approx 500^{\circ} \mathrm{C}$ [2]. Первоначально это было неочевидно. Разработанная к настоящему времени теория и опытные данные этого вида разряда при зажигании его в свободном пространстве дают величину $T$ масштаба тысячи градусов [4].

На рис. 4 помещена фоторазвертка процесса горения пропан- воздушной газовой смеси при расстоянии от инициатора до среза фокусирующего зеркала $x=22 \mathrm{~cm}$, что соответствует виду разряда, помещенному на рис. $3, d$. Временная последовательность кадров на pис. $4-$ сверху вниз. Время их экспозиции $\tau_{\exp }=1 / 24 \mathrm{~s}$.

На рис. 4 СВЧ разряд зафиксирован на втором кадре. На нем с правой стороны две яркие точки являются плазменными образованиями у концов ЭМ вибратора. Учитывая, что длительность СВЧ импульса $\tau_{\text {pul }}=40 \mu \mathrm{s}$, разряд горит только в течение $\tau_{\exp }$ этого кадра. Физика продольного неярко светящегося образования на этом кадре общей длиной $\sim 160 \mathrm{~mm}$ в настоящее время неясна. Можно предположить, что она связана с УФ излучением, исходящим из плазменных разрядных областей [6]. Правый конец этого образования определяется торцем диэлектрической заглушки кварцевой трубки. Как было указано, расстояние от инициатора до этого торца равно $24 \mathrm{~mm}$. Этот размер может служить масштабом изображений. Левый протяженный, направленный навстречу СВЧ излучению участок светящегося обра-
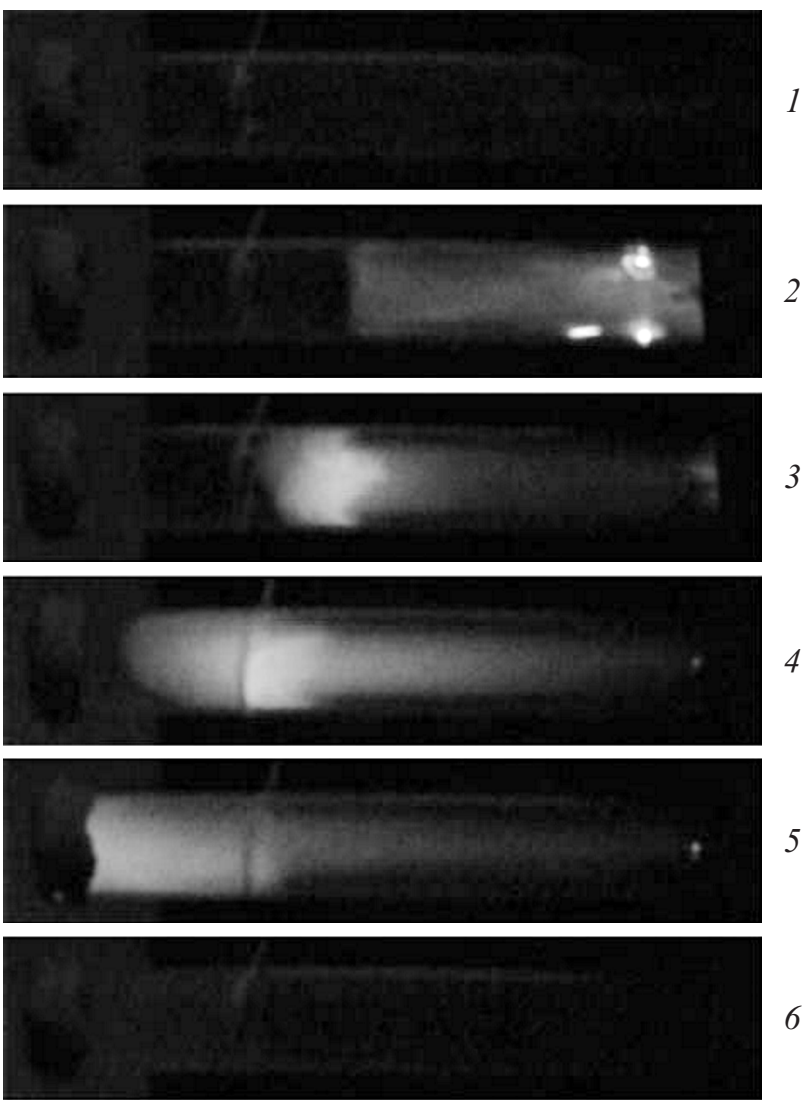

Рис. 4. Временная последовательность обычного дефлаграционного распространения пламени по заполненной пропанвоздушной горючей смесью кварцевой трубке при „точечном“ поджиге этой смеси глубоко подкритическим СВЧ разрядом.
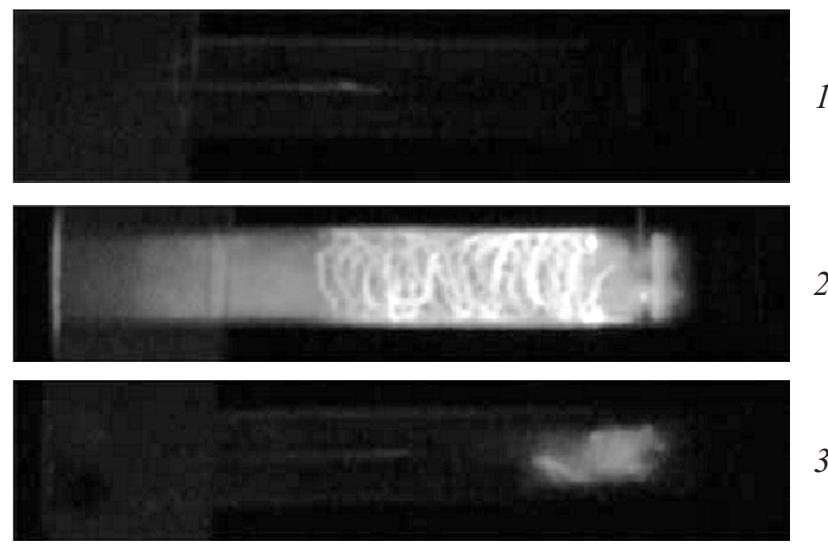

Рис. 5. Видеосъемка горения заполняющей кварцевую трубку пропан- воздушной горючей смеси при ее продольном мультиочаговом поджиге подкритическим СВЧ разрядом с поверхностно развитой стримерной структурой.

зования заканчивается резкой вертикальной границей. Физика этой ее формы также неясна.

На кадре 3 четко просматривается яркий передний фронт процесса распространения пламени, который уже 


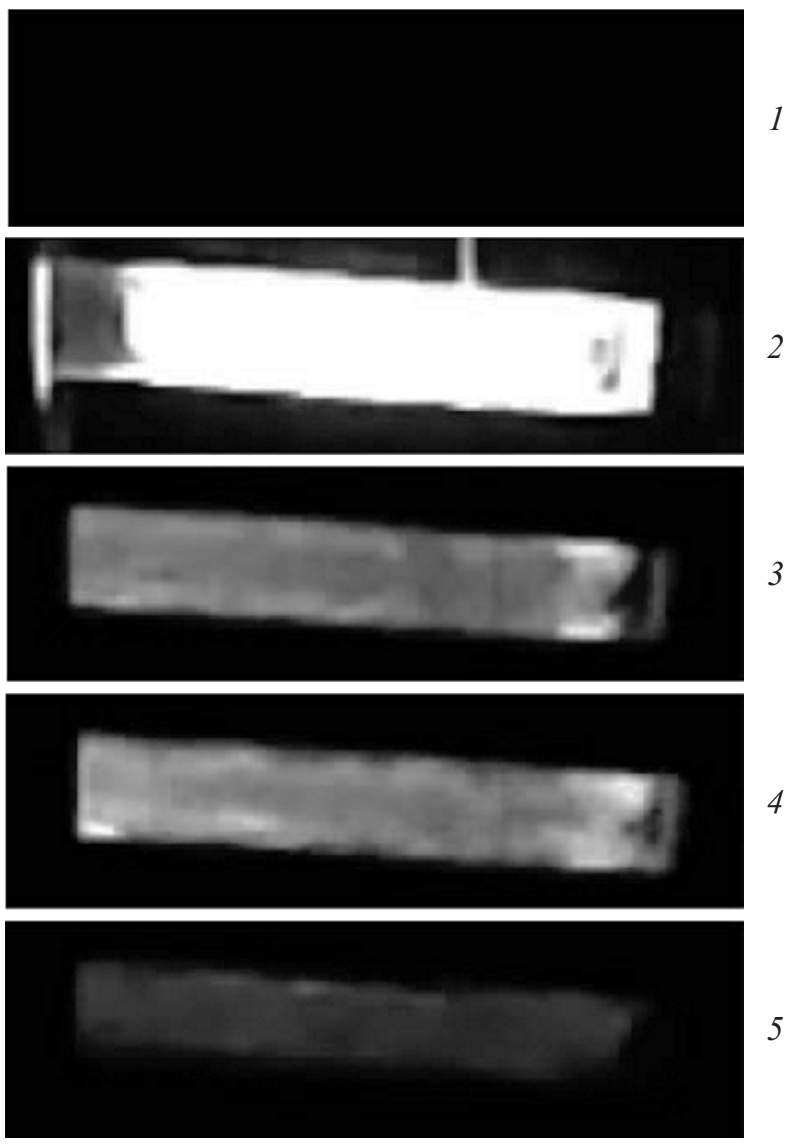

Рис. 6. Скоростная видеосъемка процесса горения заполняющей кварцевую трубку пропан-воздушной горючей смеси при ее продольном мультиочаговом поджиге подкритическим СВЧ разрядом с поверхностно развитой стримерной структурой.

в несколько видоизмененной форме зафиксирован и на кадре 4. По кадрам 3 и 4 расстояние между передними кромками этого фронта можно оценить величиной $\Delta x=67 \mathrm{~mm}$. С учетом величины $\tau_{\exp }$ этот размер дает скорость распространения фронта горения $v_{\mathrm{fr}} \approx 1.6 \mathrm{~m} / \mathrm{s}$. Эта величина является типичной для значений $v_{\mathrm{fr}}$ при его дефлаграционном распространении в трубе [2].

Из рис. 4 следует, что к кадру 6, т.е. за время $\tau_{\text {comb }} \approx 0.16 \mathrm{~s}$, процесс сгорания пропана практически заканчивается.

На рис. 5 помещена фоторазвертка процесса сгорания пропан-воздушной горючей смеси при расстоянии от инициирующего СВЧ пробой газа инициатора до среза фокусирующего зеркала $x=18 \mathrm{~cm}$, что соответствует виду разряда, зафиксированному на рис. 3, a. На рис. 5 по-прежнему $\tau_{\text {exp }}=1 / 24 \mathrm{~s}$. Из него следует, что разряд осуществил мультиочаговый поджиг горючей смеси практически одновременно по всей длине разрядной области. При этом весь процесс горения смеси не превышает времени $\tau_{\text {ехр }}$. На кадре 3 небольшая светящаяся область около правого конца кварцевой трубки регистрирует остаточный процесс догорания смеси, поступающей из тракта заполнения ею кварцевой трубки.

На рис. 6 приведена фоторазвертка этого же варианта поджига горючей смеси, но уже с $\tau_{\text {exp }}=1 / 1200 \mathrm{~s}$.

Кадр 2 этой подборки также констатирует, что разряд осуществляет мультиочаговый поджиг горючей смеси. Процесс ее сгорания иллюстрируют последующие кадры. Из них следует, что при поджиге пропан-воздушной горючей смеси таким видом разряда ее сгорание происходит за время $\tau_{\text {comb }} \approx 3.3 \mathrm{~ms}$. Это время более чем на порядок меньше определенного ранее в эксперименте времени сгорания этой смеси при ее точечном поджиге и дефлаграционном распространении пламени по смеси.

Следует также отметить, что если при дефлаграционном горении смеси герметизирующая кварцевую трубку торцевая полиэтиленфторофталатная пленка лишь слегка отходит от поверхности трубки, что, естественно, приводит к разгерметизации трубки, то при мультиочаговом поджиге горючей смеси эта пленка мгновенно „выбивается“. Связано ли это только с более быстрым сгоранием пропана в смеси или с полнотой его сгорания в настоящее время неясно и требует дальнейших количественных измерений.

\section{Заключение}

Экспериментально реализован импульсный электрический разряд в воздухе атмосферного давления в квазиоптическом СВЧ пучке на внутренней поверхности помещенной вдоль оси пучка кварцевой трубки. Определен диапазон уровня поля, в котором разряд из глубоко подкритического вида с привязанными в течение всего СВЧ импульса к концам инициатора стримерными каналами переходит в подкритический вид, в котором стримерные каналы, распространяясь навстречу ЭМ излучению, образуют поверхностно развитую систему. Экспериментально показано, что нижний концентрационный предел воспламенения пропан-воздушной горючей смеси разрядом этого вида практически совпадает с пределом ее воспламенения при поджиге электрическим разрядом „традиционного“ вида. В опытах реализованы „точечный“ поджиг пропан-воздушной смеси и обычный дефлаграционный процесс распространения фронта ее горения. Реализован и режим практически мгновенного мультиочагового поджига горючей смеси вдоль оси кварцевой трубки. При этом время сгорания горючего в смеси сокращается более чем на порядок. Вопрос увеличения эффективности его сгорания требует дальнейшего изучения.

Выполненные исследования дают основания для анализа возможности практического применения данного вида СВЧ разряда, например, в газотурбинных двигателях. 


\section{Список литературы}

[1] Зельдович Я.Б. // ЖТФ. 1940. № 1 (17). С. 1453-1461.

[2] Бартльме Ф. Газодинамика горения. М.: Энергоиздат, 1981. $279 \mathrm{c}$.

[3] Булат П.В., Ильина Е.Е. // Фундаментальные исследования. 2013. № 10, Ч. 10. С. 2140-2142.

[4] Грачев Л.П., Есаков И.И., Александров К.В., Раваев А.А., Северинов Л.Г., Ходатаев К.В. Газовый электрический разряд в квазиоптическом СВЧ пучке. М.: АО „МРТИ PAH“, 2015. 187 c.

[5] Сэйитиро Кумагаи. Горение: Пер. с японского. М.: Химия, 1979. $256 \mathrm{c}$.

[6] Богатов Н.А., Голубев С.В., Зорин В.Г. // Физика плазмы. 1986. Т. 12. Вып. 11. С. 1369-1375. 